\title{
Innovative methods of non-destructive evaluation of log quality
}

\author{
Vojtěch Ondrejka*, Tomáš Gergel', Tomáš Bucha, Michal Pástor \\ National Forest Centre - Forest Research Institute Zvolen, T. G. Masaryka 2175/22, SK - 96001 Zvolen, Slovak Republic
}

\begin{abstract}
For the sustainability of an important renewable resource, such as wood, it is important to significantly increase the efficiency of its processing. A large part of this raw material ends up in the wood processing industry, where it is used for the production of pulp, paper, construction and furniture timber, floors and others. Therefore, it is very important to gain the knowledge needed for optimal valuation of raw wood material, through quality detection and classification into quality classes. There are many defectoscopic methods working on different physical principles. The most familiar of these methods are semi-destructive and non-destructive, as they do not cause damage to the tree or wood during assessment. The aim of this article is to describe, assess and compare known semi-destructive and non-destructive methods for the assessment of wood properties. This article describes basic visual inspection, basic semi-destructive methods (Pilodyn, Resistograph) and advanced semi-destructive methods (SilviScan ${ }^{\circledR}$, $\operatorname{DiscBot}^{\circledR}$ ) as well. Non-destructive methods use mostly acoustic wave motion (acoustic, ultrasonic), high-frequency waves (using georadar, microwave) and methods based on visual evaluation (image, laser). At last, there are $\mathrm{X}$-ray methods with the latest technology using three-dimensional (3D) computed tomography (CT). The implementation of modern non-destructive methods is of great importance for the application of principles of Industry 4.0, where these methods provide collecting of data on the material properties, in its entire production flow of log processing.
\end{abstract}

Key words: X-ray method; acoustic methods; georadar methods; laser methods; industry 4.0, CT scanner

Editor: Miloš Pánek

\section{Introduction}

Today, under growing pressure from society, ecological standards and the developing industry in our country and in the world, there is an increasing emphasis on assessing the quality and origin of wood raw material. For these reasons, the European Union has developed several instruments aimed at the ecology, regulation and legalisation of harvesting. In 2003, "Forest Law Enforcement, Governance and Trade" (FLEGT) was created to prevent illegal timber trade and encourage investment in legal harvesting in developing countries. "Reducing emissions from deforestation and degradation" (REDD) offers a new method how to reduce $\mathrm{CO}_{2}$ emissions by paying for actions, to prevent deforestation or forest degradation. Rising social and ecological standards have given rise to FSC (Forest Stewardship Council) certification, which is a trusted system for forest certification and certification of the processing (consumer) chain of wood processing worldwide.

Evaluation of the quality of wood raw material and its sorting has a significant effect on maximising yield. Financial, quantitative, but also ecological reasons are important for the increasing yield. Globally, there is a great shift in the intensity of forest management and log processing, which requires significantly faster and more accurate evaluation of wood properties. Unlike concrete, bricks, steel, aluminium and most other construction materials, wood has highly complex, anisotropic and variable internal structure. For the correct use of woodand products based on it (plywood, KVH prisms, timber, OSB boards, etc.), it is necessary to evaluate the properties of this material.

There are a number of methods for evaluating wood. They can be divided, according to the degree of destruction of the evaluated material, into: 1. destructive, 2. nondestructive, 3. semi-destructive methods. Non-destructive and semi-destructive methods are more important in the evaluation of wood. Non-destructive evaluation is the identification of the physical and mechanical properties of a material without altering its end use and, using the identified properties, decides on its appropriate applications (Ross et al. 1998). In contrast, semi-destructive techniques for evaluating wood properties are defined as test procedures that are non-destructive in relation to the structural element but destructive in relation to

*Corresponding author. Vojtěch Ondrejka, e-mail:ondrejka.vojtech@gmail.com 
the extracted sample (Kasal et al. 2013). In the forestry context, non-destructive evaluation of wood (NDE) is considered attractive. Authors Schimleck, et al. (2019) described the main reasons why the NDE has grown rapidly over the last 20-25 years: Protection of investment in wood raw material; potential to reduce wood processing costs; easier to use for field measurements; fast real-time data collection; the ability to identify the most suitable measurement application and reduce the variability of product classes.

This article focuses on the description and mutual comparison of non-destructive and semi-destructive methods of wood evaluation, working on various physical principles, described from basic methods to today's most modern. The methods will be examined in relation to their use in forestry and the wood processing industry, as these sectors are significantly interrelated.

\section{Evaluation methods for wood}

The main goal of wood evaluation is to assess qualitative properties, sometimes supplemented by quantitative ones. For qualitative evaluation, it is necessary to determine the mechanical and physical properties of wood. Non-destructive methods determine, for example, mechanical properties (moduli of elasticity, impact strength etc.) and physical (moisture, density, acoustic properties, visual properties etc.). Another part of the qualitative evaluation is the determination of wood defects (knots, cracks, rot, irregularity of the wood structure, foreign objects, traces of biological damage, etc.). The identified properties significantly affect the subsequent sorting of wood products, yield and thus the financial appreciation of wood.

The basic, still widely used evaluation is visual inspection. The method is very fast, with lower costs. It allows to obtain basic information in situ about the assessed tree or log. Visual inspection allows only the detection of external, visible defects and mechanical damage to the wood. Another disadvantage is the higher demand on the expertise of the assessor, which can increase the overall cost. Visual inspection is also the basis for in situ visual classification according to the quality classes of logs and classification of construction timber into strength classes. Visual evaluation is strongly represented in supplier-customer relations in log trading. Here, the log is most often sorted according to the standards STN EN 1316-1 - 3 for broadleaf raw material and STN EN 1927-1 - 3 for coniferous raw material. These standards determine the evaluation parameters of raw logs for classification into four classes (A, B, C, D). Results of the visual inspection form the basis from which subsequent non-destructive testing (NDT) can be planned (Piaza et al. 2008). To evaluate the quality of wood, a large number of devices have been developed that can assess the properties of timber logs, veneers and other wood products.

\subsection{Semi-destructive methods}

Semi-destructive methods damage the material only partially without affecting its further use. They are used mainly to evaluate the properties of wood, logs, or historic roof constructions. A new approach to the historic roof structures properties assessment is described in the publication (Kloiber et al. 2015). The authors describe recently developed assessment methods such as tensile strength of small samples, tensile Young's modulus of mesospecimens, compression strength of cores, compression strength in a drilled hole, mechanical resistance to pin pushing, Young's modulus derived by measuring the hardness and shear strength of screw withdrawals. They do not belong to the industrially used methods, they are used mainly for scientific work. They are described here for their use in evaluating the quality of trees, which helps in the classification of wood according to quality, already in the first phase (standing tree).

Pilodyn is a portable tool for evaluating the density of trees or wooden constructions. The tool was originally developed in Switzerland to obtain quantitative data on the degree of soft rot in wooden poles. The tip penetrates the surface of the material, measuring the depth of penetration (Cown 1978). The penetration depth of the pin negatively correlates with the density of the wood. Three different rods (diameter 2.0, 2.5 and $3.0 \mathrm{~mm}$ ) enable to adapt the use of Pilodyn to the density of tested wood (Gao et al. 2017). In practice, the accuracy of Pilodyn is somewhat limited, so it is mainly used to estimate average values (Cown 1978). It is one of the least invasive sampling techniques, but unfortunately it cannot penetrate the middle layers of the trunk. It is also assumed that tested wood is above the fiber saturation point (FSP), as the penetration of the tip decreases with decreasing moisture content below the FSP (Llana et al. 2018).

The resistograph began to develop in the early $1990 \mathrm{~s}$ (Rinn et al. 1996). It was utilised for improving the identification of rot in trees and poles. The tool drives a special drill (needle) with a diameter of $3 \mathrm{~mm}$ through a tree at a given feed speed and rotation speed (rpm) and measures the resistance to rotation (torque). The trace represents the resistance profile every $0.1 \mathrm{~mm}$ and the radial change in wood density (Rinn et al. 1996; Downes \& Lausberg 2016). Gao et al. (2017) concluded that compared to other semi-destructive techniques, Resistograph was a cheaper and faster method for collecting wood density data. The key features of this tool are its low cost for field use, digital data collection and relatively high-resolution data (Schimleck et al. 2019). Research by Kloppenburg, (2018) focused on the possibility of using the Resistograph to accurately assess the wood density of tropical hardwoods. The tool has proven to be suitable, but the sharpness of the tool has a significant effect on accuracy.

Specific devices are SilviScan ${ }^{\circledR}$ and DiscBot ${ }^{\circledR}$. Both of these devices are developed more for laboratory evaluation of wood (logs, timber). They are more invasive, as it 
is necessary to take a sample (a prism, a disc) for evaluation. The first of these, the SilviScan ${ }^{\circledR}$, is a special laboratory device designed to measure wood quality parameters such as the density and angle of microfibrils (Schimleck et al. 2002). The device was created by Dr. Robert Evans and developed with his CSIRO team as early as 1992. So far, 3 versions of this device have been created. The main components of SilviScan are (Schimleck et al. 2019):

- Optical cell scanner (radial and tangential tracheid and fiber diameters, vessel size and their position, a boundary and orientation of annual rings);

- X-ray densitometer (conditioned density profile, fiber tilt, annual ring transition);

- X-ray diffractometer (microfibril angle, tracheid and fiber 3D orientation, cellulose crystallisation).

A stiffness estimate generated by SilviScan ${ }^{\circledast}$ is based on the diffractometric and densitometric properties of wood, calibrated by the acoustic resonance technique (Ilic 2001). The device has been tested in many studies and has proven to be very accurate (Buksnowitz et al. 2008; Schimleck et al. 2002).

Another special device is the DiscBot, developed by the New Zealand company SCION. The device utilises scanning technologies, which can determine a large number of wood properties affecting the resulting quality of timber and other final products. The scanner uses automatic motion of wooden discs under various sensors that capture information on wood density, microfibril angle and chemical composition. The first sensor is a camcorder for capturing a high-quality colour image (in an RGB spectrum), which allows the identification of wood defects such as knots, resin pockets and compression wood. A spectrograph fitted with an infrared (NIR) camcorder (900-1700 nm) applied in several studies (Jones et al. 2006; Thumm et al. 2010) is used to determine the chemical composition and properties of lignin and cellulose. The wood density is measured using X-rays. The strength of wood is evaluated using an ultrasonic device when the wave passes through the wood along the fibers.

\subsection{Non-destructive methods}

Non-destructive evaluation is the identification of the physical and mechanical properties of a material without altering its end use and, using the identified properties, decides on its appropriate applications (Ross et al. 1998). Previously, non-destructive methods were applied to evaluate very valuable (e.g. exotic) wood species. Currently, these methods are increasingly preferred, because they do not degrade the raw material (wood), they are accurate and are fast. This is applied mainly in automated modern sawmills, where the identified parameters help to better evaluate the processed raw material. The most commonly used physical principles in non-destructive evaluation are: acoustic, ultrasonic, microwave, imaging, laser and X-ray.

\subsubsection{Acoustic and ultrasonic methods}

Acoustic methods of wood evaluation are among the oldest methods of evaluating the properties of wood. As defined in (Lipta el al. 1972), acoustic velocity is in a form of transitional elastic waves generated by the rapid release of energy in a material. Thus, the source is an acoustic impulse, such as a hammer impact, or an excited acoustic signal (sound). Therefore, scanning the speed of acoustic waves in wood is most often used for evaluation. Another non-destructive acoustic method is ultrasonic measurement. Ultrasound is a mechanical wave with a frequency generally greater than $20 \mathrm{kHz}$ (Wang et al. 2002). The diagnostic tools operate with frequencies in the range from $20 \mathrm{kHz}$ to $500 \mathrm{kHz}$. During the measurement, ultrasonic waves to the object are generated and subsequently the transmitted waves are measured to identify the transmission properties of wood (Österberg 2009). To increase the contact of ultrasonic receivers and transmitters, it has proven appropriate to immerse the examined wood into a water bath (McDonald 1978; Han \& Birkeland 1992).
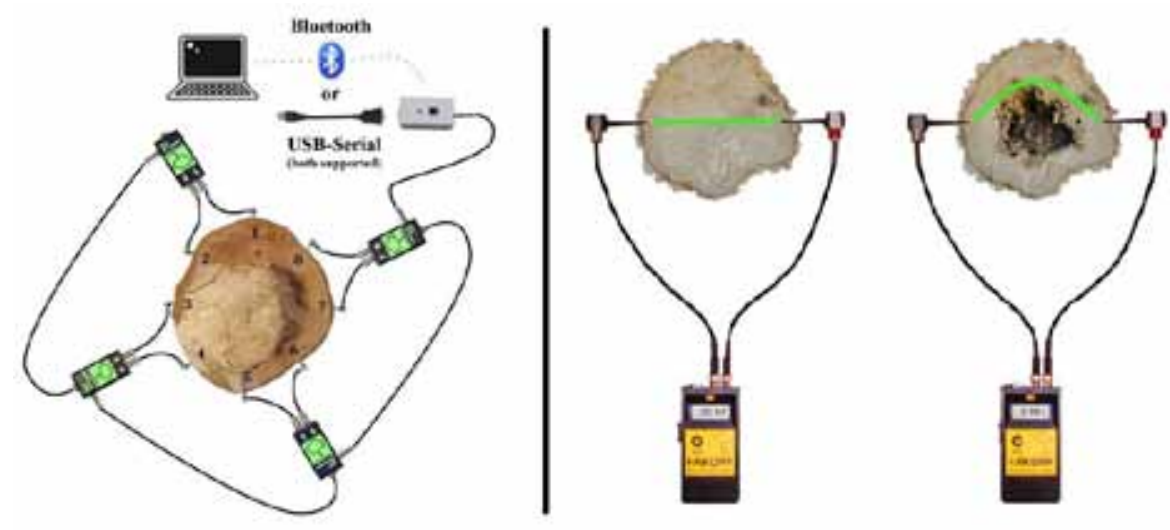

Fig. 1. Principle of measurement by acoustic tools: FAKOPP, a TreeSonic ${ }^{\mathrm{TM}}$ model and Microsecond Timer. 
The development of acoustic devices for the evaluation of standing trees opened the way for assessing the properties of tree wood before their harvesting. This facilitates the management, planning of harvest and wood processing in a way that maximizes the value extracted from the source (Riggio et al. 2008; Carter 2017). In the last few decades, acoustic technologies have become well-established devices for material evaluation in the wood processing industry. They have become a widely accepted tool for quality control and product classification (Wang et al. 2004), but also for breeding research, where they are utilised for evaluation of young trees (Lenz et al. 2013).

Most acoustic devices that evaluate the properties of trees are modelled for radial measurement (perpendicular to the trunk axis). For example, these devices: ArborSonic 3D Acoustic Tomograph, Hitman Resonance Tool, IML Impulse Hammer, and FAKOPP company tools (Microsecond Timer, Resonance Log Grader, ArborElectro Impedance Tomograph) (Fig. 1). In contrast to these tools, the FAKOPP TreeSonic ${ }^{\mathrm{TM}}$ is developed for measuring in the longitudinal direction of the trunk (Fig. 2). In acoustic systems, the source of the impulse is most often the hammer impact.

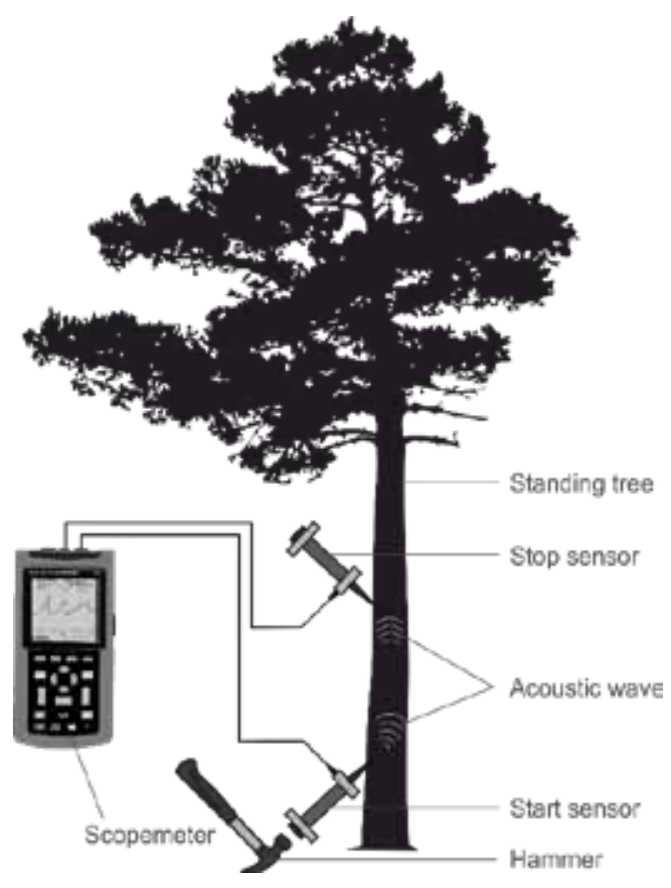

Fig. 2. Acoustic system for measuring standing trees in the longitudinal direction.

Ultrasonic systems evaluate the material mainly perpendicular to the fibers (Fig. 3). The most used ultrasonic devices are FAKOPP IltraSonic Timer, Arborsonic Decay Detector, Sylvatest, V-Meter MK IV System, Proceq Pundit Lab + , Pundit 250 Array and Tico. Most tools evaluate the quality of wood using the determined dynamic modulus of elasticity and density. When evaluating the moduli of elasticity by acoustic tools, different values may occur when repeating the measurement, which causes some inaccuracies in the results, see research: Lindström et al. (2009), Simic et al. (2019).

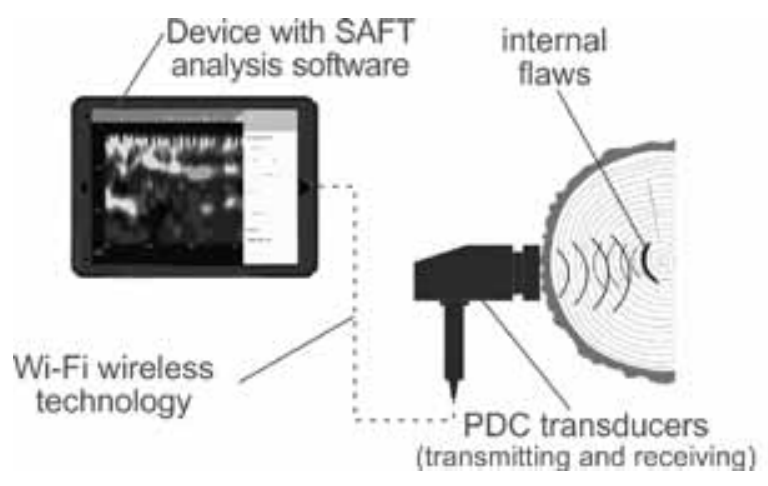

Fig. 3. Illustration of the principle of ultrasonic tomography.

All the mentioned devices are difficult to apply to rapid industrial production. That is why fast acoustic tools are being developed today, measuring at a feed speed of 200 pieces per minute. An example is the Swedish company DYNALYSE, which offers Dynagrade and Precigrade devices for evaluating timber properties. Others are devices for evaluating logs before cutting them. A company based in New Zealand, Fiber-gen, has developed the HITMAN PH330 measuring tools implemented into a forest harvester, the HITMAN LG640 for log processing lines and the HITMAN HM200 manual tool.

\subsubsection{Microwave methods}

The microwave frequency in the electromagnetic spectrum is between the frequencies of infrared radiation and high-frequency waves, i.e. approximately between the frequencies $1 \mathrm{GHz}$ and $100 \mathrm{GHz}$, or a wavelength between $1 \mathrm{~mm}$ to $1 \mathrm{~m}$ (Fuller 1990). However, the boundary between microwaves and infrared or radio waves has not been precisely defined. The microwave scanning method has been under development for several years. The first tools were created to measure moisture and were also applied in industrial production (Tiuri \& Heikkilä 1979). At present, research using microwave tomography is known, where the authors describe the detection of internal wood defects with higher accuracy (Pastorino et al. 2015; Boero et al. 2018). Using this technique, it is possible to determine properties such as: density and moisture of wood, deflection and direction of fibers or detection of wood defects as well.

Microwave induced thermo-acoustic tomography (MITAT) combining microwave imaging with ultrasonography. This special technology is mainly used in biomedicine and is still under development and the subject of much research (Ku \& Wang 2001; Meaney et al. 2012; Rosenthal et al. 2012; Wang et al. 2013). Research 
using this technology to determine the properties of wood is known. Authors Zhang et al. (2019) use the thermoacoustic principle combining microwaves and ultrasonic waves for spatial imaging of a hole in a wood sample. The method proves fast and efficient.

\subsubsection{Georadar methods (GPR)}

This method utilises electromagnetic radiation in the microwave band, high-frequency radio waves $(10 \mathrm{MHz}$ $-2.6 \mathrm{GHz}$ ) and detects reflected signals from subsurface structures of materials. (July 2008). This technology is most often used for the evaluation of soils, rocks and building elements (concrete, brick walls). However, many studies have pointed to the possibility of using this ground-penetrating technology to evaluate internal wood defects (Nicotti et al. 2003; Muller 2003; Hislop et al. 2009), where microwave radiation with a frequency of $1.5-2.5 \mathrm{GHz}$ is recommended. For the evaluation of wood, mainly devices for construction industry are used. Pirouz et al. (2015) in their research compares image, laser, X-ray scanning and technologies using GPR. He uses a device by a Sensors \& Software company, namely a Pulse $\mathrm{EKKO}^{\circledR}$ type intended for the evaluation of internal rot.

Further research uses similar devices by a GSSI company, namely SIR 3000, SIR 4000 (Senalik et al. 2016). The only device designed directly for the evaluation of wood, or on trees, is TRU ${ }^{\mathrm{TM}}$ (Tree Radar Unit) by the American company TreeRadar ${ }^{\mathrm{TM}}$ (Wen et al. 2016).

The study (Halabe et al. 2009) showed that GPR can be used to accurately identify internal defects such as knots, cracks, and metal nails that are not commonly visible. Scanning speed, good repeatability and the ability to detect wood moisture are the advantages of this technology. The disadvantage is the limited ability to detect small defects and the complexity of data processing as algorithms for evaluation are still under development. The technology is proving very promising for use in the sawmill indust.

\subsubsection{Image and laser methods}

The ever-increasing capacities of sawmills and the speed of log processing are forcing wood processors to introduce efficient and fast methods of material evaluation. Various machine vision systems (machine vision) in frequent combination with laser, acoustic and other systems have proven to be suitable solutions. Today, these systems are among the most widely used in modern industrial production, also in the wood processing industry. Computer vision, which deals with the acquisition, processing, analysis and understanding of digital images most often obtained from cameras, camcorders, 3D scanners and other scanning devices, is considered the basis of this method. Its task is to develop theoreti- cal and algorithmic bases for achieving automatic visual understanding (Sonka et al. 2014). Image technology has also become a part of most of these non-destructive scanning methods.

Many authors deal with evaluation methods by means of image technology that utilises analysis of shadows, shades of grey or colour spectrum (e.g. RGB) obtained with the help of camcorders (Hu et al. 2004; Sandak \& Tanaka 2005; Faria et al. 2008). Most of the systems used in the wood processing industry can be considered as 2D systems. These systems are mainly used for timber evaluation. Today, more and more 3D scanning technologies using lasers are coming to the fore, with their use mainly for scanning logs in sawmills. Studies dealing with the scanning of standing trees using LiDAR scanners to achieve the evaluation of surface defects before their harvesting, is known (Pirouz et al. 2015; Sauter et al. 2017). In spatial (3D) laser scanning, controlled operation of laser beams is combined with a laser rangefinder. Using specialized software, the shape of the surface of objects can be quickly captured.

The laser was first utilised to irradiate samples when measuring wood in the 1980s. The laser and camcorder were first combined to measure the dimensions. Later, dynamic laser dispersion was also used, e.g. to measure grain orientation (Österberg, 2009). Authors Kowal et al. (2012) and Sioma (2015) deal with the use of 3D images in automatic detection and localization of defects on the wood surface using the laser triangulation method. The work of Thomas et al. (2007) is aimed at scanning the surface of hardwood logs to determine their external defects.

There are several variants of a laser scanner, some with multiple laser beams and one camcorder, while other scanners have two camcorders and one laser. For example, following manufacturers offer the laser scanning method: Cognex (a model: 3D-A5000, In-Sight 9000), JoeScan (a model: JS-25-x-SERIES), LMI Technologies (a model: chroma + scan series, Gocator 2100 Series); SICK (a model: TriSpector 100).

\subsubsection{X-ray methods}

In the second half of the 1980 s, X-ray image methods were in the research phase. Methods developed for use in medicine have been transferred to the wood processing industry (Österberg 2009). Efficient commercial X-ray devices for $\log$ and timber evaluation are currently available. The device can detect internal defects of wood, hidden foreign objects, measure properties such as wood structure, moisture and density. However, due to its high cost, X-ray computed tomography (CT) is used only in the largest sawmills. Conventional X-ray scanners are usually based on discrete $X$-ray scanning in 1-4 directions (sometimes 6), where the object or source of $\mathrm{X}$-rays does not rotate (Grundberg \& Grönlund 1997). The difficulty is that even an expensive scanner with six 
X-ray directions cannot provide an accuracy similar to that obtainable by the CT scanner (Oja 1997). For these reasons, CT X-ray scanners are coming to the fore today.

There are four generations of CT scanner technology that are known. The first and second generation scan in parallel, the third and fourth generation use rotary fanshaped scanning, where an object or source of an X-ray beam moves. First generation scanners (Fig. 4a) use a single $\mathrm{X}$-ray detector. The $\mathrm{X}$-ray beam passes through the scanned object and measures $X$-ray intensities through parallel paths in that object (Schmoldt et al. 1998). They are very simple, affordable but slow. The second generation (Fig. 4b) uses a detector system consisting of multiple X-ray detectors for scanning. It's also simpler, faster, but collects unnecessary large amounts of data with frequent noise. The third generation of CT scanners (Fig. 4c) uses an array of detectors with many detectors usually placed in an arc. These devices are more complex for data processing, but are more accurate. For smaller objects, they collect unnecessary amounts of data and are expensive. The fourth generation (Fig. 4d) has a larger number of detectors placed in a circle. Here, an $\mathrm{X}$-ray source revolves around a scanned object, which is placed on a table. It can produce very accurate $3 \mathrm{D}$ images. The fourth generation has the same disadvantages as the third generation but owing to the large number of detectors it is more expensive.

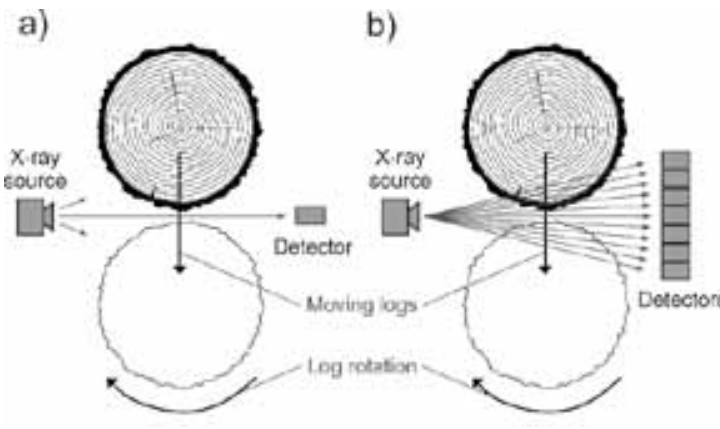

et al. 2019). Determining internal properties such as pith, core, knots, cracks and others is another their use (Stängle et al. 2015; Rais et al. 2017). CT wood scanning technology is also used for determining the content and flow of water in wood (Hansson et al. 2017; Longuetaud et al. 2017). A substantial part of the research is devoted to mathematical algorithms for evaluating the acquired images. Images for the above mentioned research are obtained mainly by means of CT scanners intended for medicine, but there are also modern industrial devices intended for the wood processing industry.

The best known manufacturers of medical macro CT scanners are Siemens and GE Healthcare. There are several manufacturers of micro CT scanners on the market, which are designed for smaller objects that they can scan with higher resolution. These are, for example, BRUKER (SkyScan series), ZEISS (Xradia series), Nikon (Model XT H 225). The Belgian Ghent University (models: EMCT, Hector, Herakles, Nanowood) also developed its devices for micro CT scanning. Other device designed mainly for timber evaluation uses $\mathrm{X}$-rays in combination with other methods (laser, image scanning). Well-known manufacturers are: WEINIG Gruppe (Model CombiScan +), Innovativ Vision (Model WoodEye 5), Microtec (Goldeneye series).

There are very few manufacturers of industrial X-ray scanners designed to scan logs. One of the manufacturers

Fig. 4 Generations of CT scanners: a) 1st generation, b) 2nd generation, c) 3rd generation, d) 4th generation.

Most modern CT scanners (4th generation) are equipped with the possibility of spiral CT scanning, which provides almost perfect volumetric reconstruction created from CT images (Beaulieu \& Dutilleul 2019). Studies by Schmoldt et al. (1998), Gupta et al. (2004) deal with the design of a tangential CT scanner, where when scanning the detector field is placed parallel to the axis of rotation of the object, parallel to the length of the log. Unlike a typical scanning, where the beam is parallel to the width of the log. This technology is patented (Gupta 1997), but its use in industry is not known.

CT X-ray scanning is becoming more and more affordable, so there is a quantity of research arising for this technology. They are utilised to determine the density of wood and the size of annual increments in coniferous and broadleaf species (Longuetaud et al. 2017; Jacquin is the German Jörg Elektronik with its JORO-X model with two X-ray sources. The second is a 3D laser scanner with multi-sensor camcorders and an X-ray scanner placed in two positions, produced by the MICROTEC $^{\circledR}$ company (Logeye series). The Italian company MICROTEC ${ }^{\circledR}$ is the best known and most advanced company dedicated to the field of CT scanners for the wood processing industry. Its CT $\log$ device (Fig. 5) is the only known device in the world designed for $3 \mathrm{D}$ log scanning. The device scans and digitally reconstructs the internal properties of the log what allows to optimise the cutting plan in real time (Microtec 2019). The developed software optimises the bending of the log, determines the best cutting plan to achieve the highest possible quality of the final product. So far, 8 of these devices have been installed in the world (Table 1). 


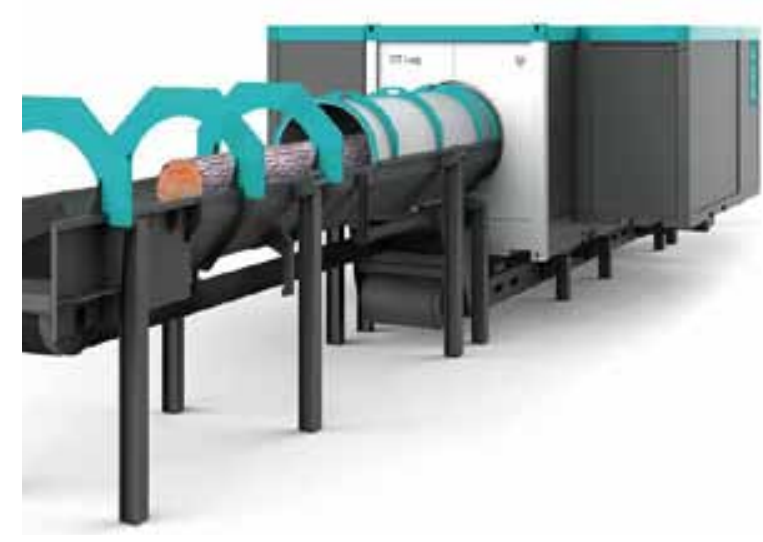

Fig. 5. CT Log scanner. (C) Microtec (Microtec 2019).

Table 1. Overview of CT Log device installations.

\begin{tabular}{|c|c|c|}
\hline State & Number of CT Logs & Company \\
\hline Canada & 1 & Interforest Ltd. \\
\hline USA & 2 & Danzer Services, Inc. \\
\hline Chile & 1 & Arauco-Horcones \\
\hline France & 2 & $\begin{array}{l}\text { Piveteaubois } \\
\text { Siat Braun }\end{array}$ \\
\hline $\begin{array}{l}\text { Germany } \\
\text { Sweden }\end{array}$ & $\begin{array}{l}1 \\
1\end{array}$ & $\begin{array}{l}\text { HIT Holzindustrie Torgau } \\
\text { Norra Timber }\end{array}$ \\
\hline
\end{tabular}

\section{Applicability and efficiency of methods}

Current trends, such as rising costs and limited supplies of quality logs, are causing the increase in efforts to maximise yields in the wood processing industry processing coniferous and hardwood tree species. The production of timber is considerably complicated, due to the high demands on the operation, complexity of the sorting, and the requirements for the accuracy of the sawmill equipment. For these reasons, in today's wood processing industry, all process stages are increasingly being modernized and automated. A great benefit for improving yield by automatic cut optimisation is also the introduction of various scanning systems to detect internal wood defects. To a greater extent, these technologies are now used in large sawmills focused on coniferous raw material. However, they are of great importance for cutting more expensive hardwood species.

In terms of applicability, we can divide non-destructive methods into two main categories, i.e. used only for research and applicable for research and industrial practice. Semi-destructive methods are used mainly for research. Most of them are applied in dendrology and forestry for the evaluation of young and older trees. The Pilodin and Resistograph devices are often used in Central Europe. Their utilization is also in wood degradation assessment of roof structures. SilviScan ${ }^{\circledR}$ and DiscBot ${ }^{\circledR}$ devices are very specific not being in Central Europe. Their use in rapid industrial production is very limited. Other methods (microwave methods, methods using georadar) are still under development and further research will be needed for their use in industry, ideally in collaboration with practice. However, there are a number of publications appearing that prove the applicability of these methods.

Described technologies enable different levels of non-destructive evaluation. Österberg (2009) created a table (Table 2), which is suitable for a clear comparison of individual methods. Indicates the level of technology acquisition costs, application level, safety, and suitability for identifying selected features.

It can be deduced from the table that the X-ray method is the most suitable for the evaluation of most parameters. These devices are less wide-spread due to their high prices. In Europe, there are only 4 industrial CT scanners located in France, Sweden and in Germany in terms of the closest distance (see Table 1). Other types of technologies are laser and image ones. Considering that these two technologies are combined in most industrial devices, we can also consider them very suitable for wood evaluation. Laser, image and also acoustic methods are therefore the most used in industrial practice. Their great advantage is affordability as well as advanced

Table 2. Evaluation of individual technologies according to their possibilities.

\begin{tabular}{|c|c|c|c|c|c|c|c|}
\hline & Laser & IR & Visible light & Acoustics & Radio frequencies & $\mu$-waves & X-ray \\
\hline Cost & +++ & ++ & +++ & ++ & + & + & --- \\
\hline Applicability & +++ & - & +++ & + & - & ++ & + \\
\hline Safety & - & +++ & +++ & t++ & ++ & + & -- \\
\hline \multicolumn{8}{|l|}{ Performance: } \\
\hline 3D-shape & +++ & $++t^{2}$ & +++ & --- & --- & - & +++ \\
\hline Rot and decay & --- & + & - & t+ & - & -- & t+t \\
\hline Colour defects & --- & --- & ++ & --- & -- & --- & --- \\
\hline Compression and tension wood & --- & - & + & + & + & + & +++ \\
\hline Cracks and splits & --- & + & + & ++ & - & + & ++ \\
\hline Resin pockets & --- & - & -- & -- & - & + & ++ \\
\hline Foreign objects & --- & - & -- & + & ++ & ++ & +++ \\
\hline Knots & --- & + & + & - & + & ++ & +++ \\
\hline Wood density & --- & - & ++ & ++ & + & ++ & +++ \\
\hline Strength & ++ & + & ++ & + & + & + & +++ \\
\hline Annual ring width & --- & - & +++ & --- & --- & --- & + \\
\hline Grain orientation & $+++^{1}$ & --- & + & --- & + & ++ & ++ \\
\hline Moisture content & --- & ++ & --- & -- & + & ++ & ++ \\
\hline Bark content & $++^{1}$ & -- & +++ & --- & --- & --- & +++ \\
\hline Fiber properties & --- & --- & - & --- & --- & --- & - \\
\hline
\end{tabular}

${ }^{1}$ when combined with image analysis; ${ }^{2}$ is not thermography, i.e. no spectral content is utilised; -- the technology is completely unsuitable for determining the mentioned characteristics; +++ the technology is suitable for determining the mentioned characteristics; Commercially known techniques. 
computer vision technology for image analysis. This results in the possibility of accurate evaluation at high speeds, applicable in fast automated production. Laser, image and acoustic methods, often combined with IR radiation, are used in all large, automated sawmills in Europe. Gradually, however, they started to be used in medium-sized sawmills. These devices are produced e.g. by WEINIG Gruppe, Innovativ Vision, MICROTEC ${ }^{\circledR}$. MICROTEC ${ }^{\circledR}$ equipment is used in the Czech Republic e.g. by sawmills Mayr-Melnhof Holz Paskov Ltd., Holz Schiller Ltd., Danzer Ltd. In Slovakia there are PRP Ltd. and Rettenmeier Tatra Timber. From these three methods, only the acoustic method has the ability of the evaluation of internal wood structures. Investment in these methods is very important for market competitiveness, especially for large and medium-sized sawmills. Return on investment ranges from 2 to 8 years. The most accurate non-destructive method for evaluating properties is certainly the $\mathrm{X}$-ray method with computed tomography (CT). These devices are slowly applied in modern wood processing plants. The big disadvantage is the high purchase price, which allows the use of this technology mainly in medium and large plants. Gergel' et al. (2019) confirmed this from the existing research and concluded that there is a demonstrable increase in the profit gained from processed wood from $11.3 \%$ to $23.7 \%$ for coniferous logs and by $24 \%$ for broadleaf logs. In processing broadleaf raw material, the return period for large sawmills is about 3 years and for medium sawmills 8 years. In processing coniferous raw material, the return period is about 4 years for large sawmills and 8 years for medium sawmills.

The Italian Microrec ${ }^{\circledR}$ company, which offers technologies using all the mentioned methods (acoustic, image, laser, X-ray), is the important company in the development of these automation technologies. In all technological industries, the Industry 4.0 application comes to the fore, or the modernization and automation of production lines, associated with the need to obtain a large amount of data on material. The Microrec ${ }^{\circledR}$ company has developed the Sawmill 4.0 - Digital Fingerprint system, which applies their non-destructive wood evaluation technologies to achieve the greatest possible automation of coniferous and broadleaf wood cutting. Combination of their devices (CT Log, Logeye, Goldeneye) and the implementation of artificial intelligence allows to create a record for each board that is monitored throughout the process. This makes it possible to qualitatively classify the final products and thus make the most of them.

\section{Conclusion}

Analysis of existing methods for evaluating the quality of wood properties, using semi-destructive and nondestructive technology. Semi-destructive technologies can be used mainly for scientific activities and for grow- ers. Currently, some non-destructive methods are only applicable to scientific activities and their introduction into industrial practice is the future. The most widely used non-destructive methods in industry are image, laser and acoustic methods. These technologies are now more available and allow very fast evaluation of wood properties. However, the possibilities of these technologies are limited mainly to surface defects, with the exception of acoustic ones. The X-ray method, mainly using computed tomography, is certainly the most accurate method. Most X-ray devices create 2D images of the scanned material. The CT Log by Microrec ${ }^{\circledR}$ company is considered the most advanced device as it enables 3D $\mathrm{X}$-ray scanning of the log in real time. It can thus detect internal defects with high accuracy, and then choose the optimal cutting pattern to achieve the highest quality of the final product (timber).

For modern sawmills of the third millennium, it is necessary to invest in modern non-destructive methods of wood evaluation to increase the yield of a quality final product. These technologies can significantly increase competitiveness. The use of Industry 4.0, or modern automated log cutting lines, is certainly the future in the wood processing industry. Streamlining of production under Industry 4.0 anticipates achieving almost zero production downtime and transparency. This requires the processing of huge amounts of data from a variety of sensors and transducers. To process this data, special systems using machine learning, neural networks and artificial intelligence are applied. The Microrec ${ }^{\circledR}$ company applied this method and developed its own Sawmill 4.0 system - Digital Fingerprint. This technology enables to create a separate record with all the data obtained for each board from scanning the log to the final product. This facilitates a significant increase in the degree of automation on sawmills. These processes are the basis for creating a reliable system that will monitor the flow of wood from its harvest to the final product.

The implementation of these technologies within the European area is very different. Sweden, Finland and, in the area of Central Europe, Germany and Austria have a significant competitive advantage in the utilization of these technologies. These countries are significantly innovating and automating the entire log processing process. Scanning technologies are used only at the two largest sawmills in Slovakia, but they are gradually started to be used by medium-sized log processors. It is strongly recommended to support this trend, e.g. by subsidies, because these technologies mean significant savings and improved quality of wood raw material.

\section{Acknowledgements}

This publication is the result of the project implementation: Centre of Excellence of Forest-based Industry, ITMS: 313011 S735 supported by the Research \& Development Operational Programme funded by the ERDF. and with the support of MARDSR, 
item 08V0301 - Research and development to promote forestry competitiveness (SLOVLES).

\section{References}

Beaulieu, J., Dutilleul, P., 2019: Applications of computed tomography (CT) scanning technology in forest research: a timely update and review. Canadian Journal of Forest Research, 49:1173-1188.

Boero, F., Fedeli, A., Lanini, M., Maffongelli, M., Monleone, R., Pastorino, M. et al., 2018: Microwave tomography for the inspection of wood materials: Imaging system and experimental results. IEEE Transactions on Microwave Theory and Techniques, 66:3497-3510.

Buksnowitz, C., Müller, U., Evans, R., Teischinger, A., Grabner, M., 2008: The potential of SilviScan's $\mathrm{X}$-ray diffractometry method for the rapid assessment of spiral grain in softwood, evaluated by goniometric measurements. Wood Science and Technology, 42:95-102.

Carter, P., 2017: Acoustic technology - Enhanced tools for research and operations. In: Proceedings of the 20th International Nondestructive Testing and Evaluation of Wood Symposium - 2017, Madison, WIS, USA, p. 12-15.

Cown, D. J., 1978: Comparison of the Pilodyn and torsiometer methods for the rapid assessment of wood density in living trees. New Zealand Journal of Forestry Science, 8:384-391.

Downes, G. M., Lausberg, M., 2016: Evaluation of the RESI software tool for the prediction of HM200 within pine logs sourced from multiple sites across New Zealand and Australia. NZ Solid Wood Innov, $15 \mathrm{p}$.

Faria, J., Martins, T., Ferreira, M., Santos, C., 2008: A computer vision system for color grading wood boards using fuzzy logic. In: IEEE International Symposium on Industrial Electronics - 2008, Cambridge,p. 1082-1087.

Fuller,A. B., 1990: Microwaves: an introduction to microwave theory and techniques. Pergamon Press, $326 \mathrm{p}$.

Gao, S., Wang, X., Wiemann, M. C., Brashaw, B. K., Ross, R. J., Wang, L., 2017: A critical analysis of methods for rapid and nondestructive determination of wood density in standing trees. Annals of Forest Science, 74:27.

Gergel', T., Bucha, T., Gejdoš, M., Vyhnáliková,Z., 2019: Computed tomography log scanning-high technology for forestry and forest based industry. Central European Forestry Journal, 65:51-59.

Grundberg, S., Grönlund, A., 1997: Simulated grading of logs with an x-ray log scanner-grading accuracy compared with manual grading. Scandinavian Journal of Forest Research, 12:70-76.
Gupta, N. K., Hughes, S. H. C., Isaacson, B., 2004: Tangential CT, a computed tomography method developed for industrial inspection. In: 16th World Conference on Non-Destructive Testing - 2004, Montreal,37:379-384.

Gupta, N.K., 1997:U.S. Patent No.5,648,996. Washington, DC: U.S. Patent and Trademark Office, $13 \mathrm{p}$.

Halabe, U. B., Agrawal, S., Gopalakrishnan, B., 2009: Nondestructive evaluation of wooden logs using ground penetrating radar. Nondestructive Testing and Evaluation, 24:329-346.

Han, W., Birkeland, R., 1992: Ultrasonic scanning of logs. Industrial metrology, 2:253-281.

Hansson, L., Couceiro, J., Fjellner, B. A., 2017: Estimation of shrinkage coefficients in radial and tangential directions from CT images. Wood Material Science \& Engineering, 12:251-256.

Hislop, G., Hellicar, A. D., Li, L., Greene, K., Lewis, C., Meder, R., 2009: Microwave radar for detection of resin defects in Pinus elliottii Engelm var elliottii. Holzforschung, 63:571-574.

Hu, C., Tanaka, C., Ohtani, T., 2004: Locating and identifying sound knots and dead knots on sugi by the rulebased color vision system. Journal of Wood Science, 50:115-122.

Ilic, J., 2001: Relationship among the dynamic and static elastic properties of air-dry Eucalyptus delegatensis R. Baker. Holz als Roh-und Werkstoff, 59:169-175. Jacquin, P., Mothe, F., Longuetaud, F., Billard, A., Kerfriden, B., Leban, J. M., 2019: CarDen: a software for fast measurement of wood density on increment cores by CT scanning. Computers and Electronics in Agriculture, 156:606-617.

Jones, P. D., Schimleck, L. R., Peter, G. F., Daniels, R. F., Clark, A., 2006: Nondestructive estimation of wood chemical composition of sections of radial wood strips by diffuse reflectance near infrared spectroscopy. Wood Science and Technology, 40:709-720.

Jol, H. M., 2008: Ground penetrating radar theory and applications. Elsevier, 544 p.

Kasal, B., Drdacky, M., Jirovsky, I., 2003: Semi-destructive methods for evaluation of timber structures. In: WIT Transactions on the Built Environment -2003, p. 835-842.

Kloiber, M., Drdácký, M., Machado, J. S., Piazza, M., Yamaguchi, N., 2015: Prediction of mechanical properties by means of semi-destructive methods: A review. Construction and Building Materials, 101:1215-1234.

Kloppenburg, A., 2018: Density determination of tropical hardwoods with the Resistograph-Diss. Master's Thesis, Delft University of Technology, Delft, Netherlands, $80 \mathrm{p}$.

Kowal, J., Karwat, B., Sioma, A., 2012: Using threedimensional images in the description of environment and biological structures. Polish Journal of Environmental Studies, 21:227-232. 
Ku, G., Wang, L. V., 2001: Scanning microwave-induced thermoacoustic tomography: Signal, resolution, and contrast. Medical Physics, 28:4-10.

Lenz, P., Auty, D., Achim, A., Beaulieu, J., Mackay, J., 2013: Genetic improvement of white spruce mechanical wood traits - early screening by means of acoustic velocity. Forests, 4:575-594.

Lindström, H., Reale, M., Grekin, M., 2009: Using nondestructive testing to assess modulus of elasticity of Pinus sylvestris trees. Scandinavian Journal of Forest Research, 24:247-257.

Liptai, R. G., Harris, D. O., Tatro, C. A., 1972: An introduction to acoustic emission. In: Acoustic Emission. ASTM International, p. 3-10.

Llana, D. F., Hermoso, E., Bobadilla, I., Iñiguez-Gonzalez, G., 2018: Influence of moisture content on the results of penetration and withdrawal resistance measurements on softwoods. Holzforschung, 72:549555.

Longuetaud, F., Mothe, F., Santenoise, P., Diop, N., Dlouha, J., Fournier, M. et al., 2017: Patterns of within-stem variations in wood specific gravity and water content for five temperate tree species. Annals of Forest Science, 74: 64.

McDonald, K. A., 1978: Lumber Defect Detection by Ultrasonics. Department of Agriculture, Forest Service, Forest products laboratory, Medison, WIS., 23 p.

Meaney, P. M., Goodwin, D., Golnabi, A. H., Zhou, T., Pallone, M., Geimer, S. D. et al., 2012: Clinical microwave tomographic imaging of the calcaneus: A firstin-human case study of two subjects. IEEE Transactions on Biomedical Engineering, 59:3304-3313.

Muller, W., 2003: Timber girder inspection using ground penetrating radar. Insight-Non-Destructive Testing and Condition Monitoring, 45:809-812.

Nicolotti, G., Socco, L. V., Martinis, R., Godio, A., Sambuelli, L., 2003: Application and comparison of three tomographic techniques for detection of decay in trees. Journal of Arboriculture, 29:66-78.

Oja, J., 1997: A comparison between three different methods of measuring knot parameters in Picea abies. Scandinavian Journal of Forest Research, 12:311-315.

Österberg, P., 2009: Wood quality and geometry measurements based on cross section images - Diss. Thesis. Tampere University of Technology, Tampere, $192 \mathrm{p}$.

Pastorino, M., Randazzo, A., Fedeli, A., Salvadè, A., Poretti, S., Maffongelli, M. et al., 2015: A microwave tomographic system for wood characterization in the forest products industry. Wood Material Science \& Engineering, 10:75-85.

Piazza, M., Riggio, M., 2008: Visual strength-grading and NDT of timber in traditional structures. Journal of Building Appraisal, 3:267-296.

Pirouz, Z., 2015: Defect Detection Technology for Hardwood Manufacturing, FP Innovations, 85 p.
Rais, A., Ursella, E., Vicario, E., Giudiceandrea, F., 2017: The use of the first industrial X-ray CT scanner increases the lumber recovery value: case study on visually strength-graded Douglas-fir timber. Annals of Forest Science, 74:28.

Riggio, M., Anthony, R. W., Augelli, F., Kasal, B., Lechner, T., Muller, W. et al., 2014: In situ assessment of structural timber using non-destructive techniques. Materials and Structures, 47:749-766.

Rinn, F., Schweingruber, F. H., Schär, E., 1996: Resistograph and $\mathrm{X}$-ray density charts of wood. Comparative evaluation of drill resistance profiles and X-ray density charts of different wood species. Holzforschung, 50:303-311.

Rosenthal, A., Jetzfellner, T., Razansky, D., Ntziachristos, V., 2012: Efficient framework for model-based tomographic image reconstruction using wavelet packets. IEEE Transactions on Medical Imaging, 31:1346-1357

Ross, R. J., Brashew, B. K., Pellerin, R. F., 1998: Nondestructive evaluation of wood. Forest Products Journal, 48:14.

Ross, R. J., 2015: Nondestructive evaluation of wood: second edition. General Technical Report, Madison, WI: U.S. Forest Service, 169 p.

Sandak, J., Tanaka, C., 2005: Evaluation of surface smoothness using a light-sectioning shadow scanner. Journal of Wood Science, 51:270-273.

Sauter, U. H., Bruechert, F., Straudenmaier, J., 2017: Nondestructive Assessment of Wood Quality throughout Wood Supply Chain and Manufacturing Process In: Wang, X.; Senalik, C. A.; Ross, R. J., (eds.): 20th international nondestructive testing and evaluation of wood symposium. Madison, WI: US Department of Agriculture, Forest Service, Forest Products Laboratory, p. 8-13.

Senalik, C. A., Wacker, J. P., Wang, X., Jalinoos, F., 2016: Assessing the ability of ground-penetrating radar to detect fungal decay in Douglas-fir beams. In: 25th ASNT Research Symposium - 2016, New Orleans, p. 110-116.

Simic, K., Gendvilas, V., O’Reilly, C., Harte, A. M., 2019: Predicting structural timber grade-determining properties using acoustic and density measurements on young Sitka spruce trees and logs. Holzforschung, 73:139-149.

Sioma, A., 2015: Assessment of wood surface defects based on 3D image analysis. Wood Research, 60:339-350.

Schimleck, L., Dahlen, J., Apiolaza, L. A., Downes, G., Emms, G., Evans, R. et al., 2019: Non-destructive evaluation techniques and what they tell us about wood property variation. Forests, 10:728.

Schimleck, L. R., Evans, R., Matheson, A. C., 2002: Estimation of Pinus radiata D. Don clear wood properties by near-infrared spectroscopy. Journal of Wood Science, 48:132-137. 
Schmoldt, D. L., Occeña, L. G., Lynn Abbott, A., Gupta, N. K., 1998: Nondestructive evaluation of hardwood logs: CT scanning, machine vision and data utilization. Nondestructive Testing and Evaluation, 15:279-309.

Sonka, M., Hlavac, V., Boyle, R., 2014: Image processing, analysis, and machine vision. Cengage Learning, $920 \mathrm{p}$.

Stängle, S. M., Brüchert, F., Heikkila, A., Usenius, T., Usenius, A., Sauter, U. H., 2015: Potentially increased sawmill yield from hardwoods using X-ray computed tomography for knot detection. Annals of Forest Science, 72:57-65.

Thomas, L., Mili, L., Thomas, E., Shaffer, C. A., 2007: Defect detection on hardwood logs using laser scanning. Wood and Fiber Science, 38:682-695.

Thumm, A., Riddell, M., Nanayakkara, B., Harrington, J., Meder, R., 2010: Near infrared hyperspectral imaging applied to mapping chemical composition in wood samples. Journal of Near Infrared Spectroscopy, 18:507-515.

Tiuri, M., Heikkilä, S., 1979: Microwave Instrument for Accurate Moisture Measurement of Timber. In: 9th European Microwave Conference - 1979, Brighton, p. 702-705

Wang, X., Ross, R. J., 2002: Non-destructive Evaluation of Green Materials - Recent Research and Development Activities. In: Nondestructive evaluation of wood. Forest Products Society, Madison, p. 149-171.
Wang, X., Divos, F., Pilon, C., Brashaw, B. K., Ross, R. J., Pellerin, R. F., 2004: Assessment of decay in standing timber using stress wave timing nondestructive evaluation tools. US Department of Agriculture, Forest Products Laboratory, Technical Report, $147 \mathrm{p}$.

Wang, J., Zhao, Z., Song, J., Nie, Z. P., Liu, Q. H., 2013: Reconstruction of microwave absorption of multiple tumors in heterogeneous tissue for microwave-induced thermo-acoustic tomography. Progress, Electromagnetics Research, 32:57-72.

Wen, J., Gao, L., Xiao, X., Xiao, Z., Li, C., 2016: Detection and measurement of internal defects for treetrunk by GPR. International Journal of Simulation: Systems, Science and Technology, 17:9-1.

Zhang, D., He, H., Zong, C., Liu, Y., 2019: Microwave-induced thermoacoustic imaging of wood: a first demonstration. Wood Science and Technology, 53:1223-1234.

\section{Internet sources:}

FAKOPP., 2020: Manual for the ArborSonic3D acoustic tomograph. [Brochure], Available at: https://fakopp. com/en/product/arborsonic/

Microtec, 2019: CT Log Computed Tomography for the sawmill of the future. [Brochure], Available at: https://microtec.eu/assets/products/ctlog/MT-CT-Log2.pdf

Sensors \& Software. 2016: pulseEKKO - For the GPR Professional [Brochure], Available at: https://www. sensoft.ca/wp-content/uploads/2016/02/pulseEKKO-Brochure.pdf

Ward, C., 2014: SilviScan ${ }^{\mathrm{TM}}$ rapid wood analysis, CSIROpedia. Available at: https://csiropedia.csiro.au/ SilviScan-rapid-wood-analysis/ry 